\title{
Subcommunal Participation and Leadership Cohesiveness of the Chinese in Nineteenth-Century Singapore
}

\author{
MAK LAU FONG \\ National University of Singapore
}

\begin{abstract}
Using reproduced inscription data the present study examines two social facets of the Chinese in nineteenth-century Singapore. The first facet pertains to group participation (economic and social) and it was found that the average amount of donations made by the Hokkiens to their subcommunal organizations was much higher than that given by the Cantonese and Hakkas.

On the other hand, more Cantonese and Hakka people contributed to their subcommunal organizations. The interplay of differential economic status and organizational objectives is heuristic in explaining this discrepancy.

The second facet is about leadership cohesiveness of the respective subcommunal leaders, and it is derived from percentage of deviant donors which comprises mean percentage of non donors and of cross line donors. The findings show that the Hakka subcommunal leaders were least cohesive, while those of the Chang-Ch'uan Hokkiens most among the four dialect groups being studied. Differential exposure to secret society influence is given as an important explanatory factor. Nepotism prevailing at the leadership hierarchy is also suggested as a crucial factor.
\end{abstract}

\section{Introduction}

That an ethnic group may be segmented by speech affinity is not uncommon. But that speech difference serves as a primary source for social identity and behavioural motivation is perhaps a unique feature of the Overseas Chinese in the early days. For example, in Hong Kong, o026-749X/83/0603-06oo\$o2.00 (C) 1983 Cambridge University Press. 
the Hokkiens were found to be indifferent to the 1925 General Strike spearheaded by the Hainanese (Purcell, I 964). In Singapore, the I 854 clash betwen the Hokkiens and the Teochius are said to have been resulted from the refusal of the Hokkiens to offer financial help to the rebels from Amoy (Buckley, I902:585; Read, I90 I :93). Many more conflicts of a similar nature have also been observed (e.g., Blythe, I969).

A recent study (Mak, I980) on the interaction patterns of the Chinese in nineteenth-century Singapore reveals that most communal activities held were highly exclusive to each dialect group. ${ }^{1}$ This finding and other earlier observations have thus underlined the importance of a redefinition of the term Chinese community.

A sociologically defined community is one in which all members are bonded together through sharing a common set of values and beliefs which in turn provides the source of behavioural motivation. The Durkheimian mechanical solidarity and the Tönniesian gemeinschaft sufficiently illustrate the experience of a community. But a community may be perceived in, and constructed upon, three conscious models as suggested by Ward ( 1965 ).

In her discussion on the Tanka in Hong Kong, Ward (Ig65) has extended Lévi-Strauss' conscious-unconscious models into three. One is the internal observer's model which is formulated through the socio-cultural arrangements of a subgroup. The other known as immediate model is constructed by the members of a subgroup upon their own socio-cultural system.

At a higher order is the ideological or the believed-in traditional model which is largely based on the once existing but relatively uniform belief and practice of the élite of the various subgroups concerned.

Ward (1965) theorizes further that while the ideological models held by different Chinese subgroups vary comparatively little, their various immediate models, 'on the other hand, may well be expected to show wide differences between each other, especially in those areas which the believed-in traditions do not cover...' (p. I25).

Whereas it is unquestionable that proliferation and diversification in ideological models may lead to even wider discrepancies between each immediate model, the present enquiry will be concerned only with the various immediate models found existing among the Chinese in nineteenth-century Singapore. The enquiry will be guided by related propositions revolving around two broad aspects of the socio-economic

'Both 'speech' and 'dialect' are being used here. The former term is used when a reference is made to language, but 'dialect' will be reserved for the context of social groupings. 
activities of these nineteenth-century Singapore Chinese. These two aspects, which have largely been determined by the availability of data, are group participation and leadership cohesiveness.

Economic asset is invariably a rich source of motivation for social influence. Economic élite are thus potentially more highly motivated than the economically deprived in exchanging their wealth for social influence. With an economic status appreciably higher than that of their contemporary counterparts, the Hokkiens in nineteen th-century Singapore should be expected to be more active in economic participation at the subcommunal level. In concrete terms, the Hokkiens should have donated more generously to their own subcommunal activities as compared to the Cantonese and Hakkas, for the former speech group represented well the rich merchant class while the latter poor farmers and artisans (Chen and Tan, I 972:15 $5^{-1} 7$ ). Additionally, it is found that Io out of the i 5 Chinese leaders at the societal level were of Hokkien speech origin (Yong, I 967 )..$^{2}$

Findings from a study on industrial workers' activity patterns (Form, 1973) have indicated that the economically advantaged are more actively involved in the community social activities than the less advantaged. Drawing a parallel example from the Chinese in nineteenth-century Singapore, the Hokkien people being high on the economic scale should be more enthusiastic in subcommunal involvement. In contrast, both the Cantonese and the Hakkas should be less active by virtue of their low economic status. In this regard, Imahore (I974: I I I, I45) has provided us with an observation contradictory to the aforementioned suggested proposition. He observes that the Cantonese had been able to mobilize their members en masse to take part in their own subcommunal activities. Further investigation into the relationship between economic status and social participation is thus desirable.

Again in the same study on industrial workers (Form, 1973) it is also found that the skilled workers who are generally from a better economic background have forged a more solidary social system than the poorer less skilled in both worksite interaction and union involvement. At the level of leadership solidarity, it is observed that the Hokkien leaders had appeared to be more cohesive compared to the Cantonese and Hakka

${ }^{2}$ Although the general pattern of attaining subcommunal leadership was first through being actively involved in philanthropic activities in the larger society, there were exceptions. The case of Chen Tu-sheng (Tan Tock Seng) supplies us with an example, for Chen moved upwards from the subcommunal level (Lin et al., i 975: 19). In either way, economic determinism was an explanatory factor in leadership attainment. 
leaders (Chen and Tan, I972: IO-I I, I4; Lin et al., I 975:233-40) for two reasons.

First, taking defacement of inscription stones as a sign of internal power conflict, Tan (Chen and Tan, 1972) is inclined to conclude that the Hakka subcommunal leaders were less cohesive, for he observes that a Hakka Ying Ho Kuan's (應和舘) renovation stone tablet had been mechanically defaced whereas all tablets of the Hokkiens were without any physical defacement. Second, to Tan (1972) frequent presence of partnership among the subcommunal leaders strongly suggests internal power stabilization. The constant partnerships between the contemporary Hokkien influentials, e.g., Hsueh Fo-chi (薛佛記), Chen Tu-sheng (陳篤生), Chen Chin-sheng (陳金聲) and some of their prominent descendants, are said to be clear indication of co-operation than conflict.

Partnership at the subcommunal level was, however, time specific in a historical perspective. This can be observed from the inscription data. For example, from a I 887 Ch'ung Wen Kuo (崇文閣) tablet and a I 896 Tsui Ying Shu Yuan (萃英書院) renovation tablet, both were Hokkien schools, we have not been able to trace any identifiable descendants of the families of Hsueh Fo-chi and Chen Tu-sheng, ${ }^{3}$ who had on four earlier occasions partnered the descendants of the Chen Chin-sheng family (Chen and Tan, 1972:267-74, 283-88, 29I-94).

Another noteworthy point is that ever since he had founded the Yun Chun Hui Kuan (永春會舘) in 1905 , Chen Jo-chin (陳若錦), the grandson of Chen Chin-sheng, had ceased to take any office in the Chang-Ch'uan power centre, i.e., T'ien Fu Kung (天福宫), as he previously had (Chen and Tan, I972:69-70).

Do these latter two pieces of information suggest that there had been major power conflicts among the Hokkiens, especially between the Chang-Ch'uan (漳 泉) and the Yun Chun Hokkiens? Or that they are only indicative of power diffusion or decentralization without having any implication of power conflict?

While all these observations (Chen and Tan, I972: Io-I I, I 4; Lin $e t$ al., I $975: 233-40$ ) are instructive, they are based, however, on only one or the top level of leadership hierarchy. Given the fact that most of the subcommunal organizations comprised more than one level of leadership hierarchy (e.g., Chen and Tan, I972), these observations are subject to empirical verification.

3 They might have used other pseudonyms or shop names rather than the more well-known ones. But on previous four similar occasions of which two were related to a shrine and the other two to two schools (Chen and Tan, 1972:267-274, 283-288, 29I-294), only popular shop names and/or personal names had been used. 
In brief, the present study, through examining inscription data, attempts to investigate subcommunal participation and leadership cohesiveness of four Chinese dialect groups in nineteenth-century Singapore. These two dimensions of social behaviour might be heuristic in the construction of a more exact immediate model for each of the dialect groups in question.

\section{Data and Variables}

Inscriptions on tablets and stones of various kinds constitute the primary source of data for the present study. These inscription data were collected and reproduced in a monograph entitled $A$ Collection of Singapore Chinese Inscriptions edited by Chen Chin-ho and Tan Yeokseong (1972) and foreworded by the latter. The inscriptions have been classified by the editors according to the nature of the subcommunal organizations into nine major categories as follows: temple, dialect association, public burial ground, clan shrine, school, private hospital, obituary, church and public monument. In the present study, only inscriptions of the first five categories that appeared before 1906 are used.

The bulk of the inscription pieces in question contained names of persons who had contributed to the welfare of the subcommunal organizations. While some of these inscriptions are simple in contents, many are very detailed to the extent of including the minutest amount of donation. The general format of most of the larger pieces of inscriptions begins with the title of the inscription, followed by the purpose of the erection of the tablet, the office-bearers' names and positions, names of donors, amount of donation and ends with the date of erection of the tablet.

The reliability and inclusiveness of this reproduced set of inscriptions have been checked against other similar, if partial, sources ${ }^{4}$ which appeared after the publication of the Collection. No major discrepancies have been found. ${ }^{5}$

Several key concepts or variables used in the present study need to be briefly defined in operational terms. First of all, by subcommunal leaders it

${ }^{4}$ See, for example, Jao (1969, 1972); Lin et al. (1975), and Wu (1975).

s It should be mentioned that the Collection (Chen and Tan, 1972) contained only reproductions of physically available inscribed data. This means that inscription tablets which were not actually physically available could not be included in the collection. For some of such 'omitted' data, readers may refer to various sources, especially Lin et al. (1975) and Wu (1975). 
is meant people who served at each dialect group's organizational committee of various kinds and levels, e.g. Board of Directors and Management or Canvassing Committee. These people were not necessarily at the same time leaders of the contemporary Chinese 'community' or the local society comprising other ethnic groups. The subcommunal leaders are identifiable from the committee titles given to them.

Economic participation in the present context refers to the average amount of money contributed to all subcommunal organizations by all donors as shown in the available tablets. This average amount of donated funds measures the level of economic participation. On the other hand, social participation is gauged by the average number of donors disregarding the amount of contribution. The two types of participation do not necessarily correlate with each other. In either case, the mean value is computed through dividing the total participation figures (donations or donors) by the number of subcommunal organizations throughout the relevant period.

Group cohesiveness of the subcommunal leaders may be measured in a number of ways. Two such methods mentioned above are the examination of the interlocking relationship of the subcommunal leaders and the detection of unnatural damage done to the subcommunal inscription tablets and stones. Yet another approach which is formulated out of the nature of the given data is to locate the proportion of deviant donors contained in each subcommunal organization's leadership hierarchy. A deviant donor is either a zero donor or a cross level donor.

A person who had not donated any amount of money to the subcommunal organization in which he was serving as a committee member is termed here a zero donor or non donor leader. Whereas leadership may be distinguished by its sources of legitimacy-charisma, tradition or legal sanction-the sources are achievable through an exchange of personal wealth. The fact that I $_{3}$ out of the ${ }_{5} 5$ Chinese leaders at the societal level were successful merchants (Yong, ig67), acquisition of leadership through such exchange practice had more or less become a normative pattern. A non donor leadership might then be taken as a sign of nonconformity.

A cross line donor is one who had contributed an amount of money that was larger than, or equal to, the biggest amount donated by someone in a position higher than his. In a society where personal wealth as a important source of influence and power was normative, cross line donation behaviour was probably deviant. 
Deviant behaviour may have unintended positive effects on group solidarity through arousing the group's consciousness in keeping the system boundary intact. Its intended immediate consequence, however, is largely negative in that it disrupts the equilibrium of the ongoing social system. The size of deviants is then indicative of the degree of group cohesiveness/divisiveness.

Since many subcommunal organizations under study comprised more than one level of leadership hierarchy, adjustments for the number of hierarchical levels are made. ${ }^{6}$ A large proportion of deviant donors of either category, i.e., zero or cross line donors, indicates low cohesiveness or high divisiveness among the leaders of the dialect group in question. ${ }^{7}$

\section{Analysis}

The present study covers the activity records mostly of the Cantonese, the Hakkas and the Hokkiens who may be differentiated into people from Chang-chou (漳 代), Ch'uan-chou (泉州), Yun-chun (永春), Ch'ang-t'ai (長泰), Chin-men (金門) and other localities. Evidence from the inscription data, especially that on interlocking leadership, suggests that before the twentieth century Hokkien people from the first three aforementioned localities were closely associated and related to one another. These three groups are thus treated here as a single entity and labelled as the Chang-Ch'uan Hokkiens, while the rest grossly branded as Other Hokkiens. Nevertheless, because of their fluid and unpatterned affiliation with one another (Lin et al., I975), these other Hokkiens are regarded here as an aggregate for contrasting purpose in some instances.

A short note on two excluded minority subcommunal groups may provide some useful information about the Chinese in nineteenth-century Singapore. First the Teochius: they constitute a sizeable dialect group in present Singapore but data on their representation in the nineteenth century were unfortunately scanty. Sporadically they took part in activities organized by other dialect groups throughout the

${ }^{6}$ The formula used for computing the percentage of non donor leaders, or the coefficient of cohesiveness is as follows:

(Proportion of non donor leaders of a specific line) $x$

(Proportion of cases [or tablets] containing non donor leaders) $\times$ too

7 The formula used here is essentially the same as that for computing the percentage of non donor leaders except that 'non donor' is replaced by 'cross line donor'. Analytically, a cross line donor may surpass donors at not only the immediate upper line, but any lines above. A donor who had crossed two lines is considered to have surpassed twice in the computation of the coefficient. 
period under study. The Teochius seemed to be a marginal subcommunal group.

Next the Hainanese. They are not included for analysis partly for the same reason applied to the Teochiu group, and partly due to the fact that only one piece of their inscription, i.e., the Shrine of the Fu Clan (erected 1907), has been available. For comparative analysis in an aggregate manner, a single piece of information sometimes conceals more than it reveals.

Prominent Straits-born Chinese had also been active in the Chinese subcommunal activities. Their speech origin, however, can be distinguished through their exclusive and persistent affiliative relationship with a certain dialect group. According to this principle, the Straitsborn Chen Tu-sheng, for instance, has been grouped with the Chang-Ch'uan Hokkiens.

In terms of economic achievement, the Hokkiens, particularly the Chang-Ch'uan Hokkiens are said to be the cream of the Chinese in early Singapore or the Straits Settlements. But when it comes to the exchange of wealth for subcommunal influence, to what extent did the Hokkiens outperform other dialect groups? Our findings (Table I) show that, among the three dialect groups, the top five donors who had made contributions to their respective subcommunal organizations during 1830-19o6, the Hokkiens out-proportioned the Cantonese and the Hakkas respectively by a minimum margin of three times and a maximum margin of almost eight times.

TABLE I

Ratio of Total Donation Made between a Hokkien Donor and a Cantonese/Hakka Donor, Singapore, 1830-1906

\begin{tabular}{|c|c|c|c|c|c|}
\hline \multirow[b]{2}{*}{ Items } & \multicolumn{5}{|c|}{ Donor's Position } \\
\hline & $\begin{array}{l}\text { Biggest } \\
\text { Donor }\end{array}$ & Second & Third & Fourth & Fifth \\
\hline $\begin{array}{l}\text { Ratio* } \\
\text { Donation Period: }\end{array}$ & $3 \cdot 5$ & 3.6 & $3 \cdot 4$ & 5.1 & $7 \cdot 9$ \\
\hline Hokkiens & $\begin{array}{l}\text { I } 880- \\
\text { I } 905\end{array}$ & $\begin{array}{l}1860- \\
1889\end{array}$ & $\begin{array}{l}1830- \\
1859\end{array}$ & $\begin{array}{l}\text { I 880- } \\
\text { I } 905\end{array}$ & $\begin{array}{l}1850- \\
1859\end{array}$ \\
\hline $\begin{array}{l}\text { Cantonese/ } \\
\text { Hakkas }\end{array}$ & $\begin{array}{l}\text { I } 860- \\
\text { I } 889\end{array}$ & $\begin{array}{l}\text { I900- } \\
1906\end{array}$ & $\begin{array}{l}1840^{-} \\
1899\end{array}$ & $\begin{array}{l}\text { I } 85^{\circ-} \\
\text { I } 899\end{array}$ & $\begin{array}{l}1890- \\
1906\end{array}$ \\
\hline
\end{tabular}

* The Cantonese' or the Hakka's amount of donation, whichever was larger, is taken as the base for comparison, i.e., set to 1. 
Temporal element and relative level of donation may confound the above findings since some of the key donors in question made their contributions some decades apart. However, after standardizing the time factor and relative level of donation the disparity still persists, and in some instances it becomes much larger.

Comparing only the top three donors ${ }^{8}$ at a 10 -year interval, the largest year-specific ratio was $76: \mathrm{I}$ and this refers to the third largest donors during $1880-89$ (Table 2). The ratio is in favour of the Hokkiens. On the other hand, the smallest ratios of $2:$ I between the Hokkiens and the Cantonese/Hakkas were obtained twice during $1890-99$ and once during I 860-69. The median ratio lies somewhere between 8 and I I times; none of the disparity was in favour of the Cantonese/Hakka donors.

TABLE 2

Year-Specific Ratio of Total Donation Made between a Hokkien Donor and a Cantonese/Hakka Donor, Singapore, 1830-1906

\begin{tabular}{lccccccc}
\hline & \multicolumn{6}{c}{ Year-Specific Donation Ratio* } \\
\cline { 2 - 7 } \multicolumn{1}{c}{$\begin{array}{l}\text { Donor's } \\
\text { Position }\end{array}$} & $1850-$ & $1860-$ & $1870-$ & $1880-$ & 1890- & $1900-$ \\
& 1859 & 1869 & 1879 & 1889 & 1899 & 1906 \\
\hline Biggest Donor & 14 & 8 & 15 & 3 & 3 & 3 \\
Second & 1 1 & 2 & 47 & 71 & 2 & 4 \\
Third & 29 & 4 & 40 & 76 & 2 & - \\
\hline
\end{tabular}

* The Cantonese' or the Hakka's amount of donation, whichever was larger, is set to $t$.

The overall skewed donation ratios derived from the subcommunal key donors were suggestive of the Hokkiens' higher level of economic participation in their subcommunal organizations. A more direct comparison which involves the total amount of donation given by all donors to respective subcommunal organizations also reflects the same. As can be seen in Table 3, the Hokkiens as a whole and on the average had actually out-performed the Cantonese and the Hakkas by about 3.5 times. The same table also reveals that the Chang-Ch'uan Hokkiens and Other Hokkiens each also out-performed both the Cantonese and the Hakkas in all three types of comparable subcommunal organizations, viz., dialect association, temple and burial ground.

8 The amount of donation given by the fourth and fifth order donors from the Cantonese/Hakkas are too minute to be compared with. 
TABLE 3

Between-Group Ratio of Mean Amounts of Donation* to Subcommunal

Organizations, Singapore, $1830-1906$

\begin{tabular}{lcccc}
\hline Dialect Groups & All & $\begin{array}{c}\text { Dialect } \\
\text { Associations }\end{array}$ & Temples & $\begin{array}{c}\text { Burial } \\
\text { Grounds }\end{array}$ \\
\hline $\begin{array}{l}\text { (All Hokkiens) } \\
\text { Chang-Ch'uan }\end{array}$ & $(3.5)$ & $(4.3)$ & $(7.0)$ & $(19.6)$ \\
$\begin{array}{l}\text { Hokkiens } \\
\text { Other Hokkiens }\end{array}$ & $4.1 \dagger$ & - & 13.3 & 17.6 \\
Cantonese & 2.3 & 4.3 & 4.4 & - \\
Hakkas & 1.02 & 0.3 & 1.8 & 16.9 \\
& $(\$ 2,610)$ & $(\$ 3,435)$ & $(\$ 1,182)$ & $(\$ 508)$ \\
& & & & \\
\hline
\end{tabular}

* The amount contributed by the Hakkas is set to I.o.

† Including also donations contributed to shrines and schools.

The Cantonese and the Hakka members' contributions to subcommunal organizations, which had been at low level, did not vary much (Mak, I980). Their average total amounts of contributions as presented in Table $\mathrm{I}$, were also almost identical. We thus see here that on the one hand speech difference had generated two immediate models, the Cantonese speaking and the Hakka speaking group. On the other hand, and along the line of economic power, both the Cantonese and Hakkas were envisaged as a collectivity based on the internal observer's model.

This internal observer's model of the Cantonese and the Hakkas seemed to prevail during the period, for Table 4 indicates that the Cantonese and the Hakkas were more active social participants compared to the Hokkiens. For every to Hokkiens contributing to their own subcommunal organizations there were twice as many of the Cantonese or Hakkas. Both the Kwangtung groups also out-scored the two Hokkien groups in all the three types of subcommunal activities under comparison.

However, intrinsically the two immediate models each maintained its own distinctiveness in social participatory behaviour, as is seen from the difference in participation ratio between the Cantonese and Hakkas which is just as great as that between the Hakkas and the Hokkiens. This may mean that while economic status is a sufficient condition for social stratification, stratification may not necessarily result from economic status alone.

What is more pertinent at this juncture is that since the Cantonese had scored highest in social participation, Imahore's observation that the Cantonese were the most capable social mobilizers seems vindicated. 
TABLE 4

Between-Group Ratio of Mean Number of Donors* to Subcommunal

Organizations, Singapore, $1830-1906$

\begin{tabular}{|c|c|c|c|c|}
\hline Dialect Groups & All & $\begin{array}{c}\text { Dialect } \\
\text { Associations }\end{array}$ & Temples & $\begin{array}{l}\text { Burial } \\
\text { Grounds }\end{array}$ \\
\hline Cantonese & 2.9 & 1.3 & 2.7 & 5.2 \\
\hline Hakkas & 2.0 & 1.4 & 1.8 & 1.9 \\
\hline Other Hokkiens & I. I & $\begin{array}{c}\text { I.O } \\
(255)\end{array}$ & 1.0 & - \\
\hline $\begin{array}{l}\text { Chang-Ch'uan } \\
\text { Hokkiens }\end{array}$ & $\begin{array}{c}\mathbf{I} .0 \\
\left(\mathrm{I} 8_{3} \dagger\right)\end{array}$ & - & $\begin{array}{c}1.0 \\
(208)\end{array}$ & $\begin{array}{c}\text { I.o } \\
(\text { I } 69)\end{array}$ \\
\hline
\end{tabular}

* Including persons whose names had not appeared in the reproduced set of inscriptions. Chang-Ch'uan Hokkiens' total number is set to 1.0 .

$\dagger$ Including also amounts given to shrines and schools.

From a financial point of view, to meet the minimum of building cost, thinly spread economic resources would have to be assembled through mobilizing a larger number of participants or donors. This explains well the situation which both the Cantonese and the Hakka were in. The variations between the Cantonese and the Hakkas, along the same line, will be discussed shortly after examining the problem of cohesiveness among the leaders of each subcommunity.

Deviant donation behaviour registered in the various subcommunal organizations is taken here as indicative of cohesiveness/divisiveness among subcommunal leaders. Such nonconforming behaviour consists of two components: zero and cross level donations.

In general and comparatively, the Chang-Ch'uan leaders were most cohesive. Less than one per cent of their leaders had not made any recorded financial contributions to their own subcommunal organizations; and virtually none at the first level of the leadership hierarchy (Table 5). They also scored the lowest on another index of divisiveness. Table 6 shows that the Chang-Ch'uan Hokkien leaders had the smallest percentage of cross level donors for all the comparable levels of leadership hierarchy. This finding has lent support to earlier observations (Chen and Tan, 1972: I0-I I, I 4; Lin, et al., I 975:233-40) that the Chang-Ch'uan leaders were more cohesive compared to especially the Hakka leaders.

The Hakka leaders, in contrast, were most divided, with 34 per cent of zero donors (Table 5) and 29 per cent of cross level donors. (Table 6). 
TABLE 5

Percentage of Zero Donations Among Leaders of Major Dialect Groups, Singapore, $1830-1906^{*}$

\begin{tabular}{lccccc}
\hline $\begin{array}{c}\text { Dialect } \\
\text { Groups }\end{array}$ & $\begin{array}{c}\text { All } \\
\text { Leaders }\end{array}$ & $\begin{array}{c}\text { Ist-Line } \\
\text { Leaders }\end{array}$ & $\begin{array}{c}\text { 2nd-Line } \\
\text { Leaders }\end{array}$ & $\begin{array}{c}3^{\text {rd-Line }} \\
\text { Leaders }\end{array}$ & $\begin{array}{c}4^{\text {th-Line }} \\
\text { Leaders }\end{array}$ \\
\hline $\begin{array}{c}\text { Cantonese } \\
(\mathrm{N}=5) \dagger\end{array}$ & 47 & 20 & 74 & 43 & 52 \\
$\begin{array}{c}\text { Hakkas } \\
(\mathrm{N}=9)\end{array}$ & 34 & 44 & $2 \mathrm{I}$ & 44 & - \\
$\begin{array}{c}\text { Chang-Ch'uan } \\
\text { Hokkiens } \\
(\mathrm{N}=6)\end{array}$ & .6 & 0 & II & 0 & - \\
$\begin{array}{c}\text { Other Hokkiens } \\
(\mathrm{N}=6)\end{array}$ & 13 & 31 & 21 & 0 & - \\
\hline
\end{tabular}

* For the formula used in the computation, see footnote no. 6 .

$\uparrow \mathrm{N}$ stands for number of cases or number of inscription tablets.

Considering the findings in both Tables 5 and 6, the Cantonese and Other Hokkien leaders did not exhibit any consistent pattern of deviation. This irregularity apparently discredits the explanatory power of differential economic status associated with the four dialect groups.

The puzzling question then is: What could possibly put a substantial

TABLE 6

Percentage of Cross Level Donors Among Leaders of Major Dialect Groups, Singapore, $1830-1906^{*}$

\begin{tabular}{cccccc}
\hline $\begin{array}{c}\text { Dialect } \\
\text { Groups }\end{array}$ & $\begin{array}{c}\text { All } \\
\text { Leaders }\end{array}$ & $\begin{array}{c}\text { Ist-Line } \\
\text { Leaders }\end{array}$ & $\begin{array}{c}\text { 2nd-Line } \\
\text { Leaders }\end{array}$ & $\begin{array}{c}\text { 3rd-Line } \\
\text { Leaders }\end{array}$ & $\begin{array}{c}4^{\text {th-Line }} \\
\text { Leaders }\end{array}$ \\
\hline $\begin{array}{c}\text { Cantonese } \\
(\mathrm{N}=5) \dagger\end{array}$ & 8 & 0.2 & 27 & 4 & 0.3 \\
$\begin{array}{c}\text { Hakkas } \\
(\mathrm{N}=9)\end{array}$ & 29 & $2 \mathrm{I}$ & 65 & 2 & - \\
$\begin{array}{c}\text { Chang-Ch'uan } \\
\text { Hokkiens } \\
(\mathrm{N}=6)\end{array}$ & 7 & 7 & 18 & 0.1 & - \\
$\begin{array}{c}\text { Other Hokkiens } \\
(\mathrm{N}=6)\end{array}$ & 18 & 12 & 53 & 0 & - \\
\hline
\end{tabular}

* A cross level donor is one who had donated a sum that was larger than that of some others who were at a higher line of leadership. For the computational formula see footnote no. 6 .

$+\mathrm{N}$ denotes number of cases or number of inscription tablets. 
number of deviant donors, either zero donors or cross level donors, onto the leadership hierarchy? Was it the cultural tradition of the Hakkas that had weighed up personal leadership quality vis-à-vis economic power in the case of zero donor leadership? This is a plausible explanation, for the Hakkas might have learnt the value of charisma or traditionalism from their long history of nomadic life. This being so, it nevertheless fails to account for the intention or behaviour of the cross level donors, especially where the Hakkas demonstrated having the highest percentage of cross level donors among the four dialect groups.

A convincing explanation should be one that could account for the two deviant situations. To this we propose the factor of differential exposure to secret society influence. The influence of Chinese secret societies on the subcommunities in nineteenth-century Singapore and throughout the Straits Settlements was so prevalent and profound that assessing it is always of immense significance (e.g., Blythe, I 969).

It hardly needs to be emphasized that all dialect groups had at one time or another been involved in, or exposed to, secret society activities. But more meaningfully, not all subcommunities were at the same time subject to the same degree of secret society influence. In our present case, a more relevant consideration is the extent to which the secret societies' influence had been brought in to each of the subcommunal organizations in question.

In one study (Mak, I980), secret society members had been spotted among the many patrons/donors to some subcommunal organizations. Of the I I secret society members who were concurrently also the patrons to subcommunal organizations, five were Hakkas who had taken an active part in the activities of eight Hakka organizations. Another four of Cantonese origin were associated with four Cantonese organizations. The remaining one was an active member of a Cantonese organization at one time and at yet another of a joint Cantonese-Hakka organization. However, on the other hand, only one identified secret society member of the I I was found in two Chang-Ch'uan people dominated organizations.

The Hakkas' experience with contemporary secret societies was not only a matter of magnitude, but also that of intensity. This can be illustrated by secret societies' contrived influence on the Hakkas' leadership hierarchy. For example, six of the eleven identified secret society members were in fact subcommunal leaders, and interestingly five of them were Hakkas while the remaining one a Cantonese.

What all these underline is that the Hakka subcommunal organizations were most receptive towards, or vulnerable to, the influence of 
secret societies. It might not be conclusive, but it is certainly heuristic to suggest that the higher degree of divisiveness among the Hakka subcommunal leaders could have been contributed at least in part by the interference of secret societies. In fact, these secret society members would not have to defy the hierarchical order by themselves. With their power rooted in the underworld, their surrogates could do just as good a job.

\section{Discussion and Conclusion}

Imahore (1972) observes that the Cantonese in nineteenth-century Singapore had been mass participants in their subcommunal activities. This observation does call for some clarification and elaboration, in the light of the aforementioned analysis. Of the two types of participation examined in the present study, his observation is partially right and only involves the case of social participation.

The findings presented earlier on indicate that the Hokkiens were more enthusiastic in their economic participation than both the Cantonese and Hakkas. On the whole they contributed three and a half times more than the latter. The effects of economic status on economic participation at this subcommunal level seemed to be more definitive, for on the one hand, the disparity between the Hokkiens and the Cantonese/Hakkas was enormous, and on the other, the variation between the Cantonese and the Hakkas was almost negligible.

The effects of economic status was, however, not as deterministic in the case of social participation, for the discrepancy between the Cantonese and the Hakkas was as large as that between the Hokkiens and the Hakkas. These between-group and within-group variations attenuate the explanatory power of the economic factor.

Substantively and primarily, the number of contributors is much contingent upon the economic status of the group. To complete a certain project, a wealthy group, compared to an economically inferior subcommunity, would require fewer donors simply because of its financial potential. It is also quite probable that a smaller fund-raising project would likely call for fewer donors. In contrast, by virtue of the operation of economic status and organizational goal, a less affluent subcommunity would call for a larger number of donors to complete even a project of similar size.

Assuming that the Hokkiens and the Cantonese/Hakkas had set their fund-raising targets at the same level, the former would have involved 
less of their contributors because of their better economic position. Supposing, again, that the Hokkiens had set a target which was lower than it had been implied in the inscription data, they would have had less participants than as recorded. The interplay of economic status and organizational goal thus seems to explain well the discrepancy in social participation between the Hokkiens and ihe non-Hokkiens or between the affluent and the less affluent.

Nevertheless, this explanation holds only if the difference between the two less affluent subcommunities was negligible. This was certainly not the case. The findings in Table 4 show that the number of Cantonese participants was almost 50 per cent more than that of the Hakkas'. ${ }^{9}$ For the economic status-organizational goal hypothesis to hold, one of the following two conditions must be fulfilled: Had the Hakkas usually been setting lower targets for fund raising? Or Were the Hakkas in reality more affluent than the Cantonese in nineteenth-century Singapore?

Table 3 above seems to suggest that the Hakkas were on a par with the Cantonese in terms of their organizational goal, for the Cantonese' average amount of donations was higher than that of the Hakkas by only an insignificant 2 per cent. That then leaves us with the problem of proving that the Hakkas were, apart from their economic participation so recorded, wealthier than the Cantonese throughout the period.

Unfortunately, hitherto not even circumstantial data were available to verify this proposition. The impression one could conceive through reviewing relevant literature is at best that both of these two subcommunities were almost equally economically deprived. The bulk of them had been engaged in the then much less lucrative, albeit technical and semi-professional, careers such as smithry, carpentry, pawnbroking (Mak, I98I:4I-4), farming and artisan work (Chen and Tan, I $972: 15-17$ ). The economic status and organizational goal hypothesis is thus held in abeyance.

As far as the findings and available data are concerned, Imahore's observation requires some qualification as follows: Compared to the Hakkas, the Cantonese were higher on the social participation scale. The source of such a within-group difference is undoubtedly a vital element

${ }^{9}$ When the participation ratios are standardized on the respective averaged population for the years $188_{1}$ (the earliest available census of population giving speech breakdown), 1891 and 1901 , for every 1o Hokkien donors there were 55 Cantonese and 125 Hakka donors. More relevantly, the Hakkas outnumbered the Cantonese by 2.3 times. If this order of ratio is to be compared, then the discussion that follows in the text requires the positions of the Cantonese and the Hakkas be exchanged. It must be borne in mind, however, that the inscription data coverage dates as far back as 1830 but the census population giving speech origins began only in $I 88 \mathrm{I}$. 
in constructing immediate models, but to locate it would merit a serious and separate attempt. Such an enquiry would be more fruitful if the effects of economic factor on collective participatory behaviour can be isolated before considering other stratification factors such as organizational network and cultural tradition. Until then, it can only be tentatively concluded that the interplay of economic status and organizational goal is heuristic in explaining the social participation pattern between the affluent and the less affluent.

The problem of subcommunal leadership is a less complicated and dubious one. While differential exposure to secret society influence as discussed earlier on is crucial, the comparative structure of subcommunal organizations to be presented shortly is highly suggestive.

It is evident from the inscription data (Chen and Tan, 1972) and observations based upon these data (e.g., Lin et al., I 975: I3) that the Chang-Ch'uan Hokkiens' subcommunal organizations had been mainly subject to the influence of a nucleus of a few affluent families for a four-generation length of time. For example, Hsueh Fo-chi and Chen Chin-sheng were brothers-in-law, and later Chen's son was married to Hsueh's daughter. The descendants of these two families and that of Chen Tu-sheng, another Chang-Ch'uan man, had held office in almost all of their organizations in nineteenth-century Singapore as well as Malacca and Penang.

There was even a personal touch in the many tablets kept in the Heng Shan T'ing (唒山亭). The several-time director of this shrine-cum-public burial ground, namely Hsueh Fo-chi, had erected in the shrine a number of tablets to commemorate his own family members or to record his own life experience as well as feelings. This amply reflects the extent of influence wielded by this group of families.

Both of these organizational features were not observed in the Cantonese and Hakka organizations. The presence and absence of this traditional type of subcommunal leadership could well be the best competing explanation to account for the degree of cohesiveness among the Chinese subcommunal leaders in nineteenth-century Singapore.

In short, the findings here further reinforce the adamant belief of speech identity as a very fundamental condition for building immediate models among the Chinese in nineteenth-century Singapore.

As Ward (1965) puts it, each subcommunal group is likely to practise two other models at times of exigency: the internal observer's model and the ideological model. The findings about what the Cantonese and Hakkas appeared to be similar in participation and leadership cohesiveness could have been a construct of social reality in the minds of the 
Hokkien people. Equally important and intriguing is the question whether the Cantonese and the Hakkas did perceive what they were observed, as in the case of occupational affinity described by $\mathrm{Li}$ ( $1970: 123^{-6}, 215^{-17}$ ) in his 1965 study on the Chinese in a southern Malaysia town named Muar. The answer provided by the present study is a conditional negative. The constraints posed by the nature of the data also incapacitate us from examining each subcommunal group's adjustment behaviour to the ideological model.

The present study focuses only on the overt behaviour of the various Chinese subcommunities, but not the source of behavioural motivation. What, then, is eventually needed in model construction is a comparative study of the subculture and group personality of each subcommunity.

\section{References}

Blythe, W. (1969) Chinese Secret Societies in Malaya. London: Oxford University Press.

Buckley, C. R. [1902] (1965) An Anecdotal History of Old Times in Singapore 1819-1867. Kuala Lumpur: University of Malaya Press.

Chen Ching-ho (陳檕和) and Tan Yeok-seong (陳有松) (1972) Hsin-chia-p'o hua-wen pei-ming chi lu (渐加坡華文碑鉻集銭) (A Collection of Singapore Chinese Inscriptions). Hong Kong: Chinese University of Hong Kong Press.

Form, W. H. (1973) 'Internal Stratification of the Working Class', American Sociological Review, $38,6: 697-71$.

Imahore, Seiji (今城二) [1972] (1974) Ma-lai-ya hua-jen she-hui (馬來亞華人社會) (The Chinese Society in Malaya). Trans. K. Y. Liu (劉果因). Penang, Malaysia: Penang Chiaying Association.

Jao, Tsung-i (镂宗頙) (1969) 'Hsing Ma Hua-wen pei-ke hsi nien' (A Chronological Survey on Chinese Inscriptions in Singapore and Malaya), Journal of the Chinese Society, University of Singapore, I : I I-51. Also appeared in Shu Mu Chi K'an (書目季刊) (Taipei), V, 2 and 3 (1972).

$\mathrm{Li}$, Yih-yuan (李亦園) (1965) I ko Yi-chih ti shih-chen (一個移雅的市鉃) (An Immigrant Town). Institute of Ethnology, Monograph Series B, No. 1. Nankang, Taipei: Academia Sinica.

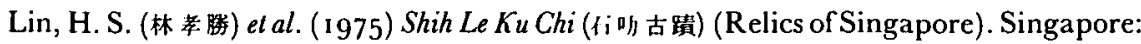
South Seas Society.

Mak, L. F. ( 1980 ) 'Rigidity of System Boundary among Major Chinese Dialect Groups in Nineteenth-Century Singapore', Modern Asian Studies, 14, 3:465-488.

( $198 \mathrm{I}$ ) The Sociology of Secret Societies. Kuala Lumpur: Oxford University Press.

Purcell, V. (1964) The Chinese in Southeast Asia. London: Oxford University Press.

Read, W. H. (1901) Play and Politics. London: Wells, Gardner, Darton \& Co.

Straits Settlements. Report on the Census of the Straits Settlements.

Ward, Barbara E. (1965) 'Varieties of the Conscious Model', M. Banton (ed.), The Relevance of Models for Social Anthropology, ASA Monograph No. 1. London: Tavistock Publications.

Wu, Hua (Ngow Wah 吴華) (1975) Hsin-chia-p’o hua-tzu hui-kuan chih (渐加坡角第咩) (A Chronological Record of Chinese Dialect Associations in Singapore). Singapore: South Seas Society ( 3 volumes).

Yong, C. F. (場進磷) ( 1967 ) 'Chinese Leadership in Nineteenth Century Singapore', Hsin-she Hsueh-pao (新社學㫼) I, I. 